\title{
Preliminary investigations into the source attribution of party sparklers using trace elemental analysis and chemometrics
}

\author{
Joshua A. D'Uva ${ }^{a, b}$, David DeTata ${ }^{c}$, Christopher D. May ${ }^{c}$, Simon W. Lewis ${ }^{a, b^{*}}$ \\ ${ }^{a}$ School of Molecular and Life Sciences, Curtin University, GPO Box U1987, Perth, Western Australia \\ 6845, Australia.
}

${ }^{b}$ Curtin Institute of Functional Molecules and Interfaces, Curtin University, GPO Box U1987, Perth, Western Australia 6845, Australia.

'ChemCentre, Manning Road, Bentley, 6102, Perth, Western Australia, Australia

*Corresponding author: s.lewis@curtin.edu.au

\section{Abstract}

In Australia, party sparklers are commonly used to initiate or prepare inorganic based homemade explosives (HMEs) as they are the most easily accessible and inexpensive pyrotechnic available on the market. As sparkler residue would be encountered in cases involving these types of devices, the characterisation and source determination of the residue would be beneficial within a forensic investigation. The aim of this study is to demonstrate the potential of using trace elemental profiling coupled with chemometric and other statistical techniques to link a variety of different sparklers to their origin. Inductively coupled plasma - mass spectrometry (ICP-MS) was used to determine the concentration of 50 elements in 48 pre-blast sparkler samples from eight sparkler brands/classes available in Australia. Extracting ground-up sparkler residue in $10 \%$ nitric acid for 24 hours was found to give the most reliable quantification. The collected data were analysed using Principal Component Analysis (PCA) to visualise the distribution of the sample data and explore whether the sparkler samples could be classified into their respective brands. ANOVA based feature selection was used to remove elements that did not significantly contribute to the separation between classes. This resulted in the development of a 7-elemental profile, consisting of $\mathrm{V}, \mathrm{Co}, \mathrm{Ni}, \mathrm{Sr}, \mathrm{Sn}, \mathrm{Sb}, \mathrm{W}$, which could be used to correctly classify the samples into eight distinct groups. Linear Discriminant Analysis (LDA) was subsequently used to construct a discriminant model using four out of six samples from each class. The model successfully classified $100 \%$ of the samples to their correct sparkler brand. The model also correctly matched $100 \%$ of the remaining samples to the correct class. This demonstrates the potential of using trace elemental analysis and chemometrics to correctly identify and discriminate between party sparklers.

Keywords: Party sparklers; Physical evidence; Inductively Coupled Plasma Mass-Spectrometry (ICPMS); Elemental profiling; Chemometrics; Principal Component Analysis (PCA) 


\subsection{Introduction}

Homemade inorganic explosives (HMEs) are frequently encountered in cases involving improvised explosive devices due to the widely available and easily accessible precursor chemicals. In Western Australia (WA), 'sparkler bombs' or other devices primarily comprised of party sparkler residue make up the majority of the HME devices seized by police. Sparklers and sparkler residue can be used to prepare an endless number of unique explosive devices. Regardless of the design, all sparkler devices have the potential to initiate fires as well as cause major damage to property, animals and people. There is a high forensic interest in analysing pre and post-blast residues from incidents involving pyrotechnics. Establishing a link between sparkler residue and its respective brand would be beneficial to forensic investigators as it may provide information regarding how they were sourced and could lead to the person/s involved. The importance of profiling and discrimination of sources for other types of physical evidence such as drugs, glass and paint has previously been demonstrated, and so further advancements in the profiling of explosive residues is warranted ${ }^{1-4}$. Therefore, an analytical approach capable of identifying the origin of sparkler material and discriminate between different sparkler brands is needed. To achieve this, analysis of pre-blast residue is first required to determine whether sparklers themselves can be classified based on their chemical composition.

Party sparklers are primarily used for festivities or celebrations and are easily purchased through local retail or online stores ${ }^{5}$. They are inexpensive, can be purchased in bulk quantities and have a long shelf life. A sparkler typically consists of a metal rod coated in an explosive mixture that burns when ignited, producing colourful sparks ${ }^{6,7}$. The chemical composition between brands vary slightly but will contain four major components which include an oxidising material, a fuel, a combustible binder and a metallic component ${ }^{6,8}$. Common oxidising agents include barium, potassium or strontium nitrate, as well as potassium chlorate or perchlorate ${ }^{5,6}$. Aluminium, iron and titanium metal powders or flakes are added to act as an accelerant or retardant. Binders such as dextrin, nitrocellulose and sugars serve a dual function in that they bind together the ingredients within the mixture and act as a fuel to promote burning ${ }^{6}$. The varying formulations used between brands may provide a unique chemical profile that could be used to differentiate between sources.

The components within an explosive mixture are routinely analysed and successfully identified using current instrumental techniques. Ion chromatography and capillary electrophoresis has shown to give the greatest sensitivity and selectivity for the analysis of cations and anions, as well as having the advantage of being field deployable ${ }^{9-12}$. Other chromatographic methods such as gas chromatography and liquid chromatography ${ }^{10,13,14}$ are routinely applied to the analysis of organic explosives, whilst less expensive methods such as FTIR and Raman spectroscopy have also been used to analyse both the inorganic and organic components ${ }^{15-17}$. Alternative techniques including SEM ${ }^{17,18}$ and ion mobility spectrometry can be used to detect a range of explosive mixtures, but cannot provide quantitative results ${ }^{19}$. While an explosive mixture can be successfully detected and identified, these techniques often do not provide enough characteristic information to distinguish between sources of the same substance.

Elemental and isotopic profiling in combination with chemometrics has previously proven to be an effective approach for linking explosive precursor chemicals to their place of manufacture and discriminating between similar sources. Isotope ratio mass spectrometry is capable of characterising and discriminating between explosive samples based on their isotopic profile ${ }^{20}$. IR-MS is commonly used to analyse nitrogen, oxygen and carbon isotopes and so it can be used on a range of inorganic and organic based explosives ${ }^{21}$. Inductively coupled plasma mass spectrometry (ICP-MS) can be used to detect and quantify a large range of elements within a sample and can therefore provide 
characteristic trace signatures ${ }^{22}$. ICP-MS has previously been successful at linking inorganic explosive precursors to their manufacturer. Fraga et al. used ICP-MS and applied variable selection methods to obtain an elemental profile that was used to classify 125 calcium ammonium nitrate (CAN) samples from six different factories ${ }^{23}$. Their approach was very effective as it was able to discriminate the CAN samples into 5 groups, one being two factories from the same company. A similar methodology was used to investigate the source determination of commercial cyanide stocks, however ionic and isotopic profiles were used in conjunction with the elemental signatures ${ }^{24}$. The potential of using IRMS for the discrimination of explosives and their precursors has also been investigated ${ }^{21}$. Benson et al. showed how the variability between the nitrogen, oxygen and hydrogen isotopes within ammonium nitrate samples could be used to differentiate between three different Australian manufactures, as well as five different overseas manufactures ${ }^{25}$. Discrimination between ammonium nitrate-based fertilisers using a combination of their isotopic and elemental composition has also been reported, which highlighted the potential of using both techniques to differentiate between sources 22 .

Sparklers primarily contain barium nitrate among a wide range of other components; therefore, the trace elemental signatures can potentially be exploited to discriminate between different brands. There are no reported studies on the source determination of party sparklers and so an analytical approach was prepared based upon previous works which investigated other inorganic explosive precursors ${ }^{9,24}$. The approach outlined in this investigation can additionally be applied to post-blast sparkler residues in future studies in order to build a model which could potentially relate post-blast and pre-blast residue.

\subsection{Materials and Methods}

\subsection{Party sparkler sample collection}

Packets of sparklers were purchased from a variety of local and online Australian retail stores. Multiple packets from eight different brands were purchased and analysed throughout the study. Investigation into the source information for each brand revealed they were all manufactured in China by different companies, however information on the specific location of each factory within China could not be obtained. The sparklers from the brand 'Party Central' were used for the preliminary experiments detailed in section 3.1. All brands were used throughout the remainder of the study. Table 1 details the source information for each brand

Table 1: List of sparkler brands used within study

\begin{tabular}{|l|l|l|}
\hline Brand name & Place of purchase & Supplier / Distributor \\
\hline We Love 2 Party (WL2P) & Big W & A.Royale \& Co \\
\hline Artwrap & Big W & IG Design Group Australia Pty Limited \\
\hline Time 2 Party (T2P) & Big W & Yatsal Distributors Pty Ltd \\
\hline Whiz pop bang (WPB) & Woolworths & Korbond \\
\hline Party Central & Red Dot & PJ SAS Trading Pty Ltd \\
\hline Fun and Creative (FC) & Ebay Australia & KD Trading PTY LTD \\
\hline Firefox & Ebay Australia & Dun Pai Fireworks group \\
\hline Wizard & $\begin{array}{l}\text { Discount party warehouse } \\
\text { online }\end{array}$ & Discount party warehouse \\
\hline
\end{tabular}




\subsection{Sample preparation}

To prepare a sparkler sample for ICP-MS analysis, all the residue was first stripped from the wire by hand. $10 \mathrm{~mL}$ of $10 \%$ nitric acid was added to $100 \mathrm{mg}$ of sparkler residue in a glass test tube that had been soaked in a $10 \%$ nitric acid solution for 2 hours. The sample was sonicated for 10 minutes, capped and left undisturbed for 24 hours. The sample was filtered into another acid washed test tube using a $25 \mathrm{~mm}$ Acrodisc $^{\circledast}(0.45 \mu \mathrm{m}$ hydrophilic polyethersulfone membrane) syringe filter attached to a $10 \mathrm{~mL}$ terumo hypodermic syringe. The sample was then diluted using a $1 \%$ nitric acid solution and analysed by ICP-MS. A 100 and 10-fold diluted sample was prepared and analysed from every sample unless otherwise stated.

\subsection{ICP-MS analysis}

ICP-MS analysis was performed using an Agilent 7900 ICP-MS (Santa Clara, CA, USA) with ISIS-3 discrete sampling introduction, coupled to an ASX-560 autosampler (Teledyne CETAC technologies, Omaha, NE, USA). The concentrations of 50 elements were determined by 6-point calibration in the range of $0.2-50 \mathrm{ppb}$ prepared from $10 \mathrm{ppm} 68$ multi-element standards $\mathrm{A}, \mathrm{B}, \mathrm{C}$ and $\mathrm{Hg}$. (Choice Analytical, NSW, AUS). Dilution was performed using a Hamilton MicroLab 600 series auto-dilutor using $1 \%$ distilled nitric acid prepared from an OmniPure acid still. ${ }^{103} \mathrm{Rh}$ and ${ }^{193} \mathrm{Ir}$ were used as internal standards and analysed under no gas, hydrogen and helium modes. The $10 \mathrm{ppb} 68$ multi-element standard A, B and C, as well as an appropriate drift solution from a previous run were used to assess quantitative drift throughout the analyses. Additional ICP-MS tune parameters are detailed in Table 2.

Table 2: Parameters and tuning settings used for ICP-MS analysis

\begin{tabular}{|l|l|}
\hline RF Power & $1550 \mathrm{~W}$ \\
\hline S/C Temp & $2^{\circ} \mathrm{C}$ \\
\hline Nebuliser Gas & $1.05 \mathrm{~L} / \mathrm{min}$ \\
\hline Auxillary Gas & $0.90 \mathrm{~L} / \mathrm{min}$ \\
\hline Plasma Gas & $15.0 \mathrm{~L} / \mathrm{min}$ \\
\hline He Flow & $4.5 \mathrm{ml} / \mathrm{min}$ \\
\hline H2 Flow & $5.0 \mathrm{ml} / \mathrm{min}$ \\
\hline Sampling time & $0.31 \mathrm{sec}$ \\
\hline
\end{tabular}

\subsection{Chemometric analysis}

Data pre-processing was carried out using Microsoft Excel and chemometric analysis was performed using the Unscrambler X 10.5 software (Camo Software AS, Oslo, Norway). Elements which presented a low number of counts $(<1000)$ from the instrument were initially removed. ANOVA based feature selection was performed on the remaining elements, which has previously proven to be an effective approach at reducing the number of classifiers in order to give greater separation between samples 23, 26, 27. F-ratios were calculated for each element in Microsoft Excel using the ANOVA class-to-class and within-class variance equations ${ }^{26}$. As the magnitude of the $f$ ratio indicates the amount of class separation, elements with the highest $f$-ratios will have a large contribution to the separation of samples. Principal component analysis (PCA) was initially carried out before feature selection was 
applied to the data set to determine whether any brands could be immediately distinguished. Scores plots were subsequently generated using up to five principal components (PCs) to visualise the distribution of sample data after removing elements that had the lowest $f$-ratios. This process was repeated until the maximum separation between classes was achieved.

Once the number of elements used for classification was refined, linear discriminant analysis (LDA) was used to construct a discriminant model. Four out of six samples from each class (total of 32 samples from 8 classes) were randomly selected and used to build the discriminant model and the remaining two samples from each class (total of 16 samples from 8 classes) were used for validation. Additionally, cross-validation was performed internally by the Unscrambler software to build the model. The calibration set was then used to predict samples from the validation set, the resulting predicted classification being compared to the actual classification to assess the accuracy of the constructed model.

\subsection{Results and Discussion}

\subsection{Preliminary experiments}

Explosives and dangerous goods laws in Australia prohibit the use of most consumer fireworks and pyrotechnics. The use of pyrotechnics is very limited outside of commercial firework displays and celebratory events. Party sparklers are the most accessible pyrotechnic available for use by the general public all year round, and therefore are most commonly used to initiate or make improvised explosive devices. Previous work has been undertaken on the characterisation of consumer fireworks and pyrotechnics as well as the environmental impact and persistence of post-blast residues ${ }^{28-30}$. However, these studies have little relevance to the Australian forensic context as most of the products investigated are not commercially available within Australia. As elemental analysis of party sparklers has yet to be reported, varying sample preparation and extraction methods were initially investigated.

The impact of the solvent, solvent strength, dilution factor and extraction time was explored using a sparkler from the brand 'Party Central'. Samples were extracted using MilliQ water, $1 \%$ nitric acid and a $1 \%$ nitric/hydrochloric acid (1:1) solution and then analysed after dilution by a factor of 1,10 and 100. It was found that extraction of $100 \mathrm{mg}$ of residue in nitric acid after dilution by a factor of 100 was the most effective. The concentration of many elements was more than double that of the samples that were extracted in the nitric/ $\mathrm{HCl}$ solution, and extraction in water yielded no signal for most elements. Subsequent experiments analysed samples extracted in 1, 5 and $10 \%$ nitric acid and samples extracted in 10\% nitric acid for 1, 2, 4 and 24 hours. It was found that the concentration for most elements were the highest when $100 \mathrm{mg}$ of residue was extracted using $10 \%$ nitric acid for 24 hours and so these parameters were used for the remaining experiments. Within a real investigation a shorter extraction time might be preferable, in which case a 4-hour extraction would be ideal. However, for the purpose of this study a longer extraction time was preferred as it resulted in a more efficient extraction.

\subsection{Discrimination of party sparkler brands}

A total of eight different brands of party sparklers commercially available within WA were analysed using ICP-MS and chemometrics to determine whether the differences in their elemental composition can be used as a discriminating feature (see Table 1). Six individual sparklers were analysed from each brand, making a total of 48 samples. The concentrations of 55 elements within the sparkler residue were determined. Many elements were found to be present in bulk and trace amounts within the sparkler residue (See supplementary information Table S1). Additionally, the concentration of most 
elements varied greatly across the brands. While the residue consisted mostly of barium, other elements such as cobalt, strontium, manganese, copper and chromium were also present in large amounts. Contact was made with one of the distributors and it was found that barium nitrate made up approximately $50 \%$ of the sparkler by weight, with iron and aluminium making up around 33 and $9 \%$ respectively. It is likely that the detected metals originate from impurities within these major components as this would explain why they are present in large amounts compared to the other elements detected. Interestingly, many trace elements such as tungsten, lead, arsenic, tin, molybdenum and antimony were also found. Again, the presence of these elements may be a result of impurities from the other inorganic and organic components, or contamination during the manufacturing process. This highlights how even though all brands were manufactured in China, the region/location of the warehouse as well as the ingredients used within the manufacturing process clearly has an impact on the concentrations of these elements in the final product. Additionally, there were no brands containing certain elements that were not present in the others, therefore none of the brands could be immediately discriminated based on the presence or absence of a certain element.

After an initial assessment of the data, elements which exhibited an extremely low number of counts $(<1000)$ were removed (Table S1). Isotope selection was also performed to minimise potential interferences and to assist in data reduction. PCA was performed using the remaining elements to show how the sparkler brands clustered before feature selection was applied to the data (Figure 1a). It was clear from initial assessment of the PCA scores plot that barium had the largest impact on clustering and contributions from other elements became almost negligible (Figure 1a). The concentration of barium was at least five times larger than every other element and so was removed from the data. When removed, PCA performed using the remaining elements reveals three distinct clusters as shown in Figure $1 \mathrm{~b}$. In an attempt to improve the separation between samples ANOVA based feature selection was performed on the remaining list of elements. F-ratios were calculated for each remaining element, therefore ranking them based on their contribution to the separation of samples. By raising the $\mathrm{f}$-ratio threshold, elements with the lowest contribution are removed from the data and PCA can be performed using the newly refined elemental profile to visualise how the samples cluster, ultimately determining whether the eight sparkler brands can be discriminated based on their elemental composition.

Table S2 details the f-ratio values for the analytes used within PCA from lowest to highest, indicating which were removed at the select thresholds. A low threshold (10-150) did not have an impact on brand discrimination as the plots generated looked near identical to the one displayed in Figure $1 \mathrm{~b}$. Three brands remained separated, with a large cluster containing the remaining five. The elements that were removed therefore did not have any major contributions to the separation of the samples. Once the threshold reached 200 and manganese was removed from the data, the 'Artwrap' sparklers could be discriminated from the other brands. The 2-D scores plot looked very similar to Figure $1 b$, however visualisation of the samples in 3-dimensions with an additional PC reveals the discrimination of four out of eight groups.

Removal of zirconium and copper had minimal impact on the scores plot, a major difference in sample clustering was first seen when zinc was removed at a f-threshold of 275. As seen in Figure 2a, PCA analysis was performed using a refined 8-element profile and total visual separation of all eight brands was achieved. This plot also highlights how little variability there is between individual sparklers, as there is minimal spread between samples within each brand. One sample from the 'Wizard' brand was found to be the only outlier as it does not cluster with any group, which could possibly be attributed to contamination during sample preparation or manufacturing. 

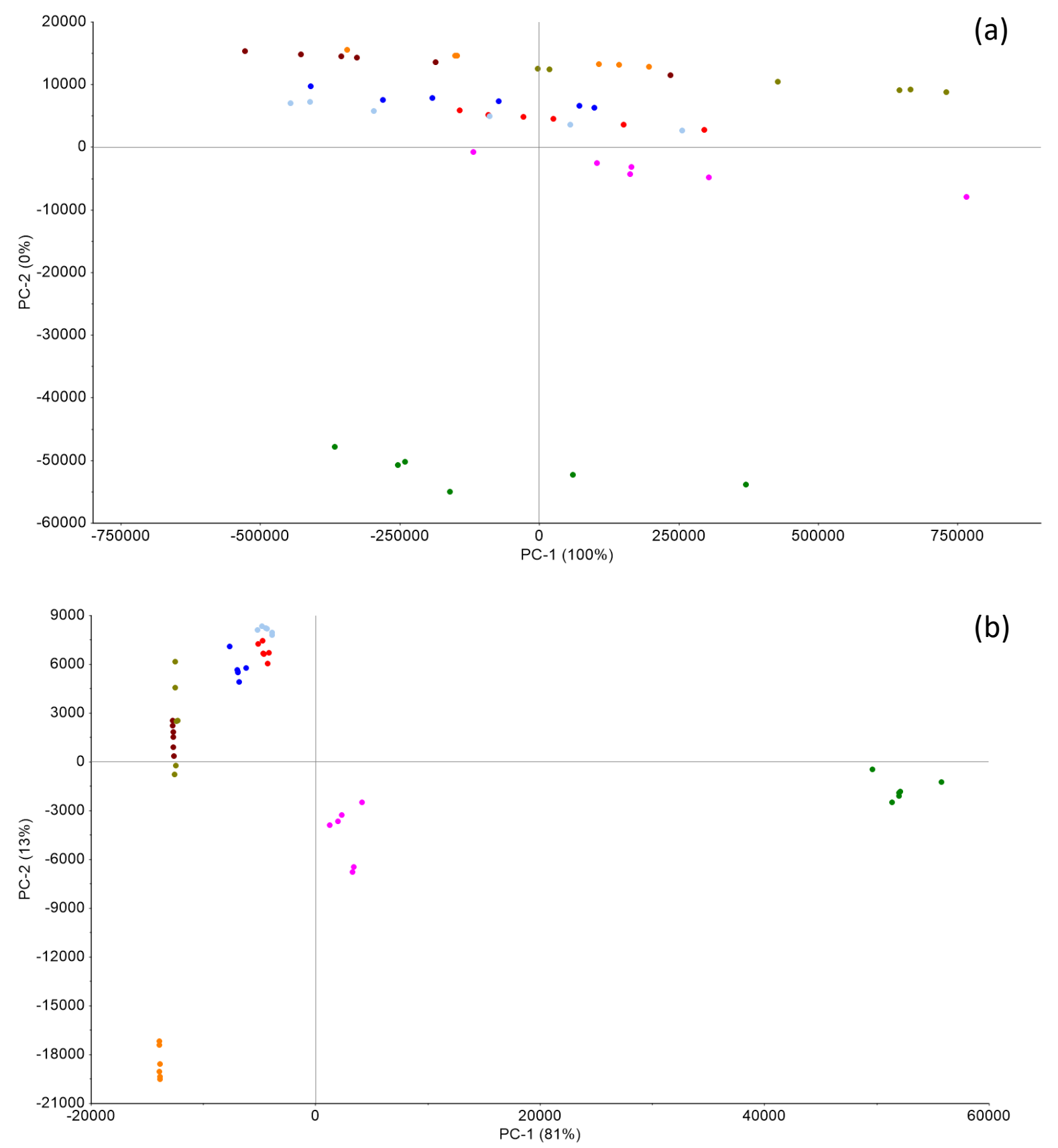

- Artwrap - We love 2 party - Time 2 party - Whiz pop bang

- Party central Fun and creative - Firefox Wizard

Figure 1: 2-dimensional PCA scores plot showing the distribution of samples before (a) and after (b) barium was removed 
(a)
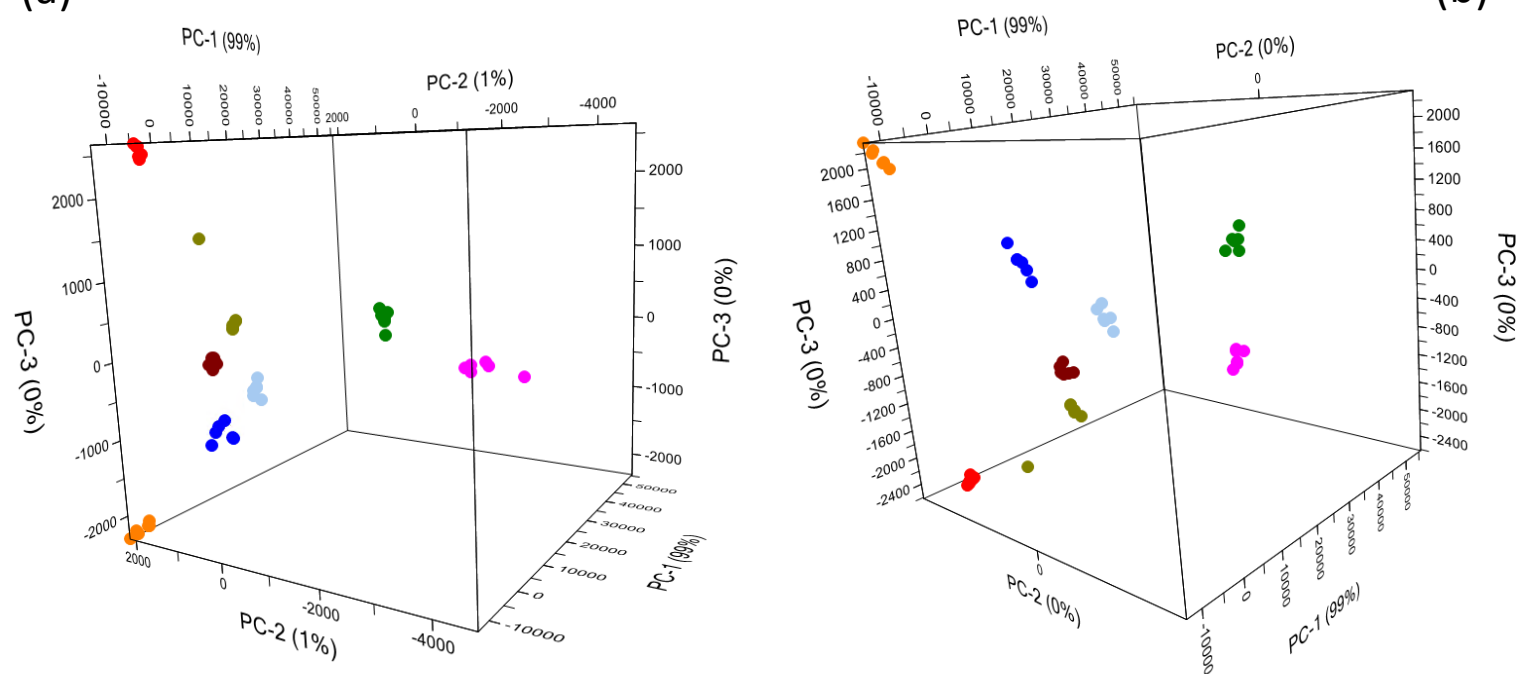

- Artwrap - We love 2 party

- Time 2 party Whiz pop bang

- Party central Fun and creative Firefox Wizard

Figure 2: 3-dimensional PCA scores plot showing the distribution of samples using quantitative data from an 8-element (a) and a 7-element profile (b)

Increasing the threshold further to 300 and removing titanium resulted in very similar clustering (Figure $2 \mathrm{~b}$ ). Total separation can still be achieved with a 7-element profile, however the amount of separation between clusters differs. Figure 3 compares the 2-D scores plot when using the 7 and 8element profile. The brand ' $T 2 \mathrm{P}^{\prime}$ ' is in the same position in both plots and when titanium is present the brand 'Firefox' has greater separation along the PC2 axis from the other brands. The remaining six clusters are much closer to each other along the PC2 axis than they are when titanium is not present, as seen in Figures $3 a$ and $3 b$. The clusters are more evenly distributed along this axis when using the concentrations from 7 elements and so this elemental profile was found to be overall more effective at discriminating between the eight sparkler brands. The factor loadings can be used to identify which elements contribute to the variation across the different PCs (Figure 4). Most of the variability between the samples is visualised across PC1, which is attributed to the concentration of strontium. The loadings from both PC2 and PC3 show that variation along these PCs are mostly due to the concentrations of nickel and copper, with small contributions from the remaining elements within the profile. 

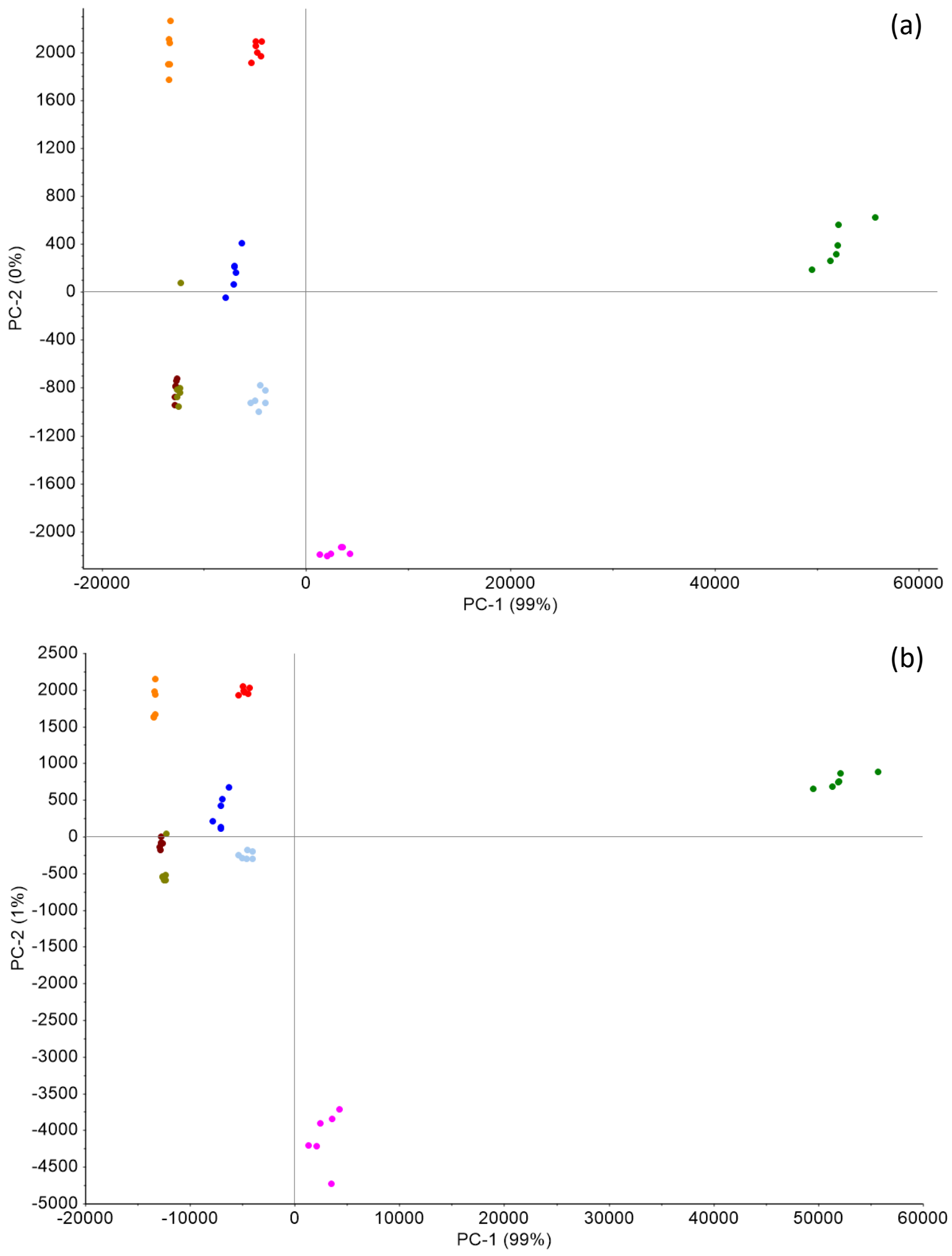

- Artwrap - We love 2 party $\quad$ Time 2 party $\quad$ Whiz pop bang

- Party central Fun and creative Firefox Wizard

Figure 3: 2-dimensional scores plot showing the distribution of samples when using an 8 (a) and 7elemental profile (b) 


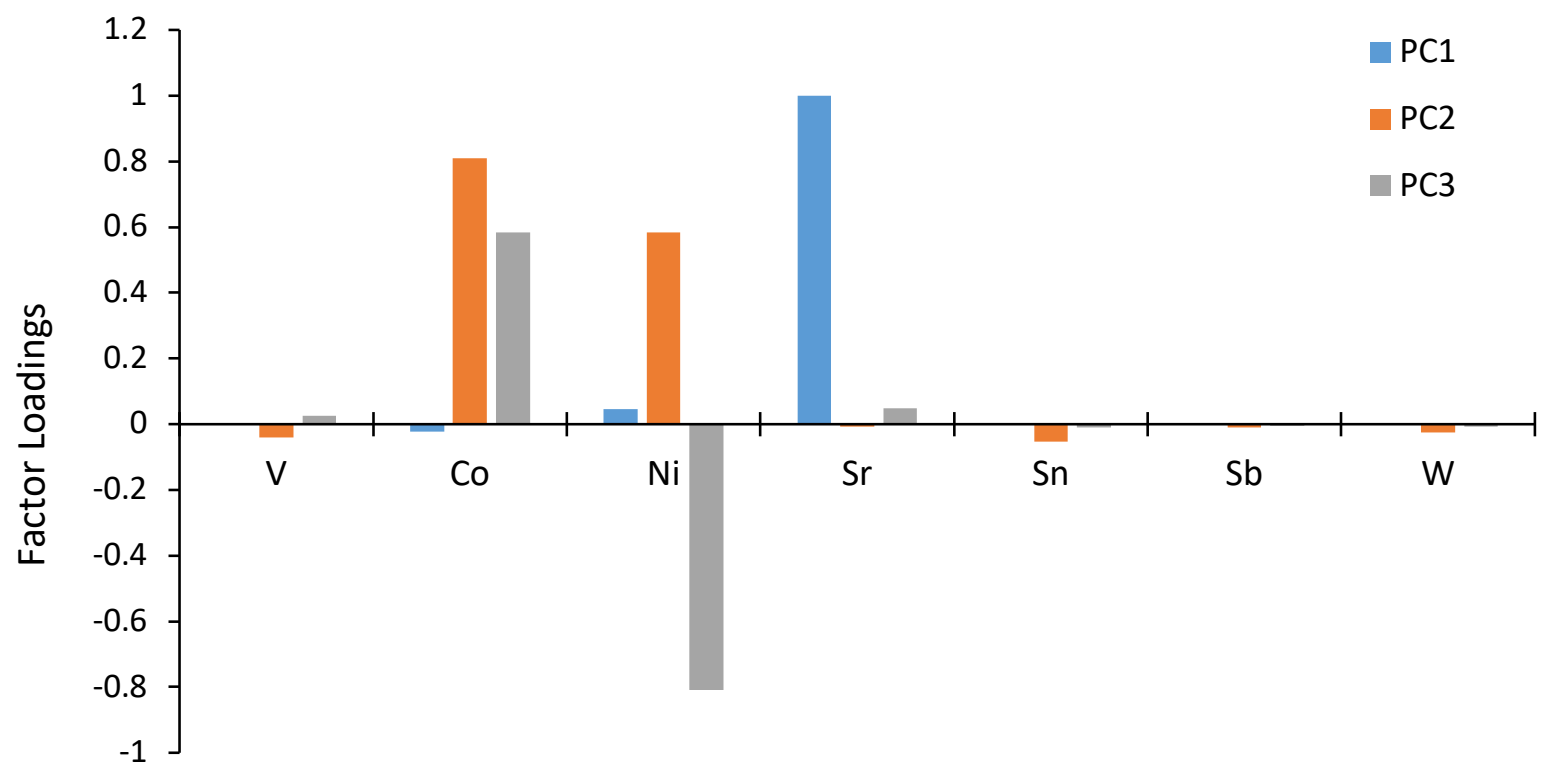

Element

Figure 4: Factor loadings of the first 3 PCs for PCA performed on the eight sparkler brands using the refined 7-elemental profile

Table 3 is a summary of the average concentration values of the elements used within the refined profile. The concentration of strontium is considerably different across each brand which is why PC1 describes most of the variation between samples. Additionally, the relative standard error is very low for most elements, which is why there appears to be minimal spread within each cluster.

Table 3: Average concentration ( $\mathrm{ppb}$ ) and relative standard deviation of elements within refined 7element classification profile

\begin{tabular}{|c|c|c|c|c|c|c|c|}
\hline Brand & $\mathbf{V}$ & Co & $\mathrm{Ni}$ & $\mathrm{Sr}$ & Sn & Sb & $\mathbf{w}$ \\
\hline WL2P & $\begin{array}{c}307 \pm \\
6.9 \%\end{array}$ & $\begin{array}{c}3.71 \times 10^{3} \pm \\
5.2 \%\end{array}$ & $\begin{array}{c}757 \pm \\
0.7 \%\end{array}$ & $\begin{array}{c}7.41 \times 10^{3} \pm \\
6.7 \%\end{array}$ & $\begin{array}{c}46.5 \pm \\
5.6 \%\end{array}$ & $\begin{array}{c}40.0 \pm \\
5.8 \%\end{array}$ & $\begin{array}{c}28.4 \pm \\
7.9 \%\end{array}$ \\
\hline Artwrap & $\begin{array}{l}138 \pm \\
2.3 \%\end{array}$ & $\begin{array}{c}3.18 \times 10^{3} \pm \\
0.9 \%\end{array}$ & $\begin{array}{c}4.68 \times 10^{3} \pm \\
2.3 \%\end{array}$ & $\begin{array}{c}9.46 \times 10^{3} \pm \\
3.9 \%\end{array}$ & $\begin{array}{l}59.1 \pm \\
16.0 \%\end{array}$ & $\begin{array}{c}36.2 \pm \\
5.9 \%\end{array}$ & $\begin{array}{c}45.2 \pm \\
4.2 \%\end{array}$ \\
\hline T2P & $\begin{array}{c}206 \pm \\
4.5 \%\end{array}$ & $\begin{array}{c}2.23 \times 10^{3} \pm \\
4.1 \%\end{array}$ & $\begin{array}{c}4.03 \times 10^{3} \pm \\
6.1 \%\end{array}$ & $\begin{array}{c}6.64 \times 10^{4} \pm \\
3.0 \%\end{array}$ & $\begin{array}{c}67.1 \pm \\
4.0 \%\end{array}$ & $\begin{array}{c}26.1 \pm \\
3.5 \%\end{array}$ & $\begin{array}{l}26.4 \pm \\
10.3 \%\end{array}$ \\
\hline WPB & $\begin{array}{l}120 \pm \\
4.4 \%\end{array}$ & $\begin{array}{c}2.46 \times 10^{3} \pm \\
4.8 \%\end{array}$ & $\begin{array}{r}689 \pm \\
6.1 \%\end{array}$ & $\begin{array}{c}9.82 \times 10^{3} \pm \\
5.6 \%\end{array}$ & $\begin{array}{c}73.3 \pm \\
3.3 \%\end{array}$ & $\begin{array}{c}45.1 \pm \\
6.9 \%\end{array}$ & $\begin{array}{l}24.0 \pm \\
14.0 \%\end{array}$ \\
\hline $\begin{array}{l}\text { Party } \\
\text { central }\end{array}$ & $\begin{array}{l}150 \pm \\
3.8 \%\end{array}$ & $\begin{array}{c}2.44 \times 10^{3} \pm \\
3.0 \%\end{array}$ & $\begin{array}{l}743 \pm \\
9.5 \%\end{array}$ & $\begin{array}{c}1.64 \times 10^{3} \pm \\
5.5 \%\end{array}$ & $\begin{array}{c}69.9 \pm \\
6.5 \%\end{array}$ & $\begin{array}{l}30.4 \pm \\
12.4 \%\end{array}$ & $\begin{array}{l}22.1 \pm \\
12.8 \%\end{array}$ \\
\hline FC & $\begin{array}{l}272 \pm \\
12.1 \%\end{array}$ & $\begin{array}{c}6.09 \times 10^{3} \pm \\
3.5 \%\end{array}$ & $\begin{array}{c}503 \pm \\
3.5 \%\end{array}$ & $\begin{array}{c}1.12 \times 10^{3} \pm \\
6.4 \%\end{array}$ & $\begin{array}{l}33.9 \pm \\
10.5 \%\end{array}$ & $\begin{array}{c}13.9 \pm \\
6.0 \%\end{array}$ & $\begin{array}{c}20.1 \pm \\
5.6 \%\end{array}$ \\
\hline Firefox & $\begin{array}{l}554 \pm \\
2.1 \%\end{array}$ & $\begin{array}{c}1.05 \times 10^{3} \pm \\
4.4 \%\end{array}$ & $\begin{array}{c}633 \pm \\
1.9 \%\end{array}$ & $\begin{array}{c}1.72 \times 10^{4} \pm \\
6.4 \%\end{array}$ & $\begin{array}{c}388 \pm \\
2.2 \%\end{array}$ & $\begin{array}{c}84.2 \pm \\
2.7 \%\end{array}$ & $\begin{array}{c}213 \pm \\
2.5 \%\end{array}$ \\
\hline Wizard & $\begin{array}{l}204 \pm \\
12.0 \%\end{array}$ & $\begin{array}{c}2.16 \times 10^{3} \pm \\
4.9 \%\end{array}$ & $\begin{array}{c}1.32 \times 10^{3} \pm \\
40.9 \%\end{array}$ & $\begin{array}{c}1.93 \times 10^{3} \pm \\
7.0 \%\end{array}$ & $\begin{array}{l}75.5 \pm \\
21.0 \%\end{array}$ & $\begin{array}{l}33.4 \pm \\
10.6 \%\end{array}$ & $\begin{array}{l}24.1 \pm \\
10.3 \%\end{array}$ \\
\hline
\end{tabular}


Increasing the threshold above 300 and removing additional elements did not improve brand discrimination. After nickel is removed, four of the groups can still be visually discriminated, however the remaining four are clustered together in the corner between the PC1 and PC2 axes. This trend continues as the threshold increases further. This is also in agreement with the loadings profile as nickel is one of the key elements linked to brand discrimination across PC's 2 and 3, with total separation becoming unattainable when it is removed. Therefore, PCA performed on the 48 sparkler samples using a 7-element profile consisting of $\mathrm{V}, \mathrm{Co}, \mathrm{Ni}, \mathrm{Sr}, \mathrm{Sn}, \mathrm{Sb}$ and $\mathrm{W}$ was found to be the most effective at discriminating the eight sparkler brands.

\subsection{Supervised classification of refined elemental profile}

It has been shown that all eight brands can be fully discriminated into visual clusters using PCA. To further assess the degree to which the samples have been separated, LDA was performed using the selected seven elements. LDA is a supervised classification technique in which a discrimination function is constructed to maximise separation between the selected classes. In this case, an LDA model was built using the first three components from the 7-element PCA with each sparkler brand being treated as a separate class. Two samples from each class were randomly removed to be used within the validation set, with the remaining four samples from each class used to build the LDA model. The validation set is used to assess how effective the model is at classifying the unknown samples into the correct class. Additionally, cross-validation was performed internally by the system to build the model. The constructed LDA model successfully produced a classification accuracy of $100 \%$ for the sparkler samples. While full separation was visualised in the final PCA scores plot (Figure 2b), four of the eight brands clustered closely together along the PC2 and PC3 axis. Nonetheless, the LDA model was still able to successfully classify all the data and achieve a $100 \%$ accuracy.

Table 4 details the average discriminant values of the samples within the calibration set. These values describe the separation between classes and reinforces how the model achieved a $100 \%$ classification accuracy. The brands ' $\mathrm{T} 2 \mathrm{P}^{\prime}$ ', ' $\mathrm{FC}$ ', and 'Firefox' are well separated from the rest, which highlights how visual interpretation of the scores plot could be misleading. In Figure $3 b$, while the 'Firefox' samples are clustered far from the rest, there appears to be minimal separation between the ' $F C^{\prime}$ and ' $T 2 \mathrm{P}^{\prime}$ clusters. Table 4 also shows that the 'Wizard' and 'Party Central' samples had the lowest amount of separation. Again, this could not easily be concluded from visualisation of the scores plot. The samples from the 'Wizard' brand appear to be closer to the 'T2P' cluster. The differences seen between the LDA and PCA results is likely attributed to the large contribution from PC1. As the variation along this $P C$ is considerably larger than the others, it is difficult to visualise the differences in the position along the PC1 axis compared to the PC2 and PC3 axis. This reinforces the importance of performing discriminant analysis in conjunction with PCA to verify results as it removes subjective interpretation. 
Table 4: Average discriminant values of the validation samples

\begin{tabular}{|l|r|r|r|r|r|r|r|r|}
\hline & \multicolumn{7}{|c|}{ Average discriminant value } \\
\hline WL2P & Artwrap & \multicolumn{1}{|c|}{ T2P } & \multicolumn{1}{|c|}{ WPB } & PC & FC & Firefox & Wizard \\
\hline WL2P & -3.6 & -171 & -2620 & -74.1 & -55.2 & -314 & -431 & -89.1 \\
\hline T2P & -170 & -2.2 & -2348 & -149 & -131 & -693 & -391 & -96.6 \\
\hline WPB & -2621 & -2350 & -4.7 & -2060 & -2665 & -4310 & -1313 & -2570 \\
\hline Party Central & -72.9 & -149 & -2057 & -2.4 & -44.7 & -678 & -157 & -47.8 \\
\hline FC & -53.8 & -131 & -2662 & -44.4 & -2.2 & -526 & -318 & -9.8 \\
\hline Firefox & -313 & -694.0 & -4309 & -679 & -527 & -3.3 & -1462 & -629 \\
\hline Wizard & -429 & -391 & -1310 & -156 & -318 & -1461 & -2.3 & -281 \\
\hline
\end{tabular}

Now that a discriminant model has been constructed, it can be used to assign the unknown samples within the validation set to the most probable class. The model was able to correctly match $100 \%$ of the samples to their source (Table 5). This was expected as even though samples used within the validation set were selected at random and some brands appeared to be less separated than others, there was minimal variation between samples within each brand. However, even though no samples were misclassified, the predictive accuracy may be over-estimated as a small data set was used to build and validate the model. A more rigorous test with additional samples from a variety of brands is required. It is possible that including a wider variety of brands within the model will no longer result in full separation. Ultimately, a larger number of distinct brands as well as the different products within a singular brand and batches of manufacture need to be analysed to truly assess the discriminatory and predictive power of this model.

Table 5: Number of correct and incorrect classifications of samples within the validation set.

\begin{tabular}{|l|c|c|c|}
\hline Class & Correct & Incorrect & \% correct \\
\hline We love 2 party & 2 & 0 & 100 \\
\hline Artwrap & 2 & 0 & 100 \\
\hline Time 2 party & 2 & 0 & 100 \\
\hline Whiz pop bang & 2 & 0 & 100 \\
\hline Party central & 2 & 0 & 100 \\
\hline Fun and creative & 2 & 0 & 100 \\
\hline Firefox & 2 & 0 & 100 \\
\hline Wizard & 2 & 0 & 100 \\
\hline
\end{tabular}

\subsection{Conclusions}

The characterisation and discrimination of a variety of party sparklers available within Western Australia was explored. ICP-MS analysis was used to determine the concentrations of 50 elements in party sparklers from eight unique brands. Experiments were first performed in which the extraction time, solvent, dilution factor and solvent concentration were varied. The most efficient extraction was observed when $100 \mathrm{mg}$ of sparkler residue was extracted in $10 \mathrm{~mL} 10 \%$ nitric acid solution for 24 hours. A wide range of bulk and trace elements were found to be present within sparkler residue which varied 
greatly across the different brands. Although each sparkler contained barium nitrate as its primary oxidiser, impurities from additional components used and contamination from the manufacturing process clearly alter the elemental composition of sparklers across brands.

Principal component analysis was then used to visualise the distribution of the sample data by generation of scores plots using up to five PCs. ANOVA based feature selection was used to calculate f-ratios for each analyte. Analytes which had the lowest f-ratios were removed from the data set and subsequent score plots were generated. Total separation of classes was achieved at a f-threshold of 300. The refined elemental profile used to classify samples into their distinct clusters included a total of 7 elements, which included; $\mathrm{V}, \mathrm{Co}, \mathrm{Ni}, \mathrm{Sr}, \mathrm{Sn}, \mathrm{Sb}, \mathrm{W}$. The discriminatory and predictive power of the elemental profile was further assessed using LDA. A discriminant model was constructed using four out of six samples from each brand, with the remaining samples used for validation. LDA yielded a $100 \%$ calibration accuracy and was subsequently used to correctly match $100 \%$ of the samples within the validation set to their respective brand.

This work illustrates the potential for the source attribution of party sparkler residue as physical evidence. Elemental analysis in combination with PCA and LDA has been demonstrated as an effective approach to discriminate between different party sparkler brands. However, the sample size is limited and so analysis of additional sparkler brands as well as similar pyrotechnic products is needed to further assess the model's effectiveness at discriminating different products. Projection of post-blast data from the same sparkler brands onto the model is also necessary to determine whether post-blast residue can be linked to its pre-blast residue and therefore its original source.

\section{Conflicts of interest}

There are no conflicts to declare.

\section{Acknowledgments}

The authors would like to thank Matt Freeman (ChemCentre) for the ICP-MS analysis and providing technical assistance throughout the study and Dr Georgina Sauzier (Curtin University) for reviewing of the draft manuscript. The authors acknowledge the facilities and funding provided by ChemCentre for the preparation and analysis of the sparkler samples. Joshua D'Uva was supported by an Australian Government Research Training Program (RTP) Scholarship.

\section{References}

1. N. Nic Daeid and R. J. Waddell, Talanta, 2005, 67, 280-285.

2. M. N. C. Grainger, M. Manley-Harris and S. Coulson, Journal of Analytical Atomic Spectrometry, 2012, 27.

3. A. L. Hobbs and J. R. Almirall, Anal Bioanal Chem, 2003, 376, 1265-1271.

4. T. Trejos, S. Montero and J. R. Almirall, Anal Bioanal Chem, 2003, 376, 1255-1264.

5. J. A. Conkling and C. J. Mocella, Chemistry of Pyrotechnics: Basic Principles and Theory, CRC Press, Boca Raton, FL, 2011.

6. R. Betha and R. Balasubramanian, Aerosol and Air Quality Research, 2013, 13, 301-307.

7. H. D. McManus, V. F. Wiqal and R. S. Long, Patent 3862865, 1975.

8. C. Martín-Alberca and C. García-Ruiz, TrAC Trends in Analytical Chemistry, 2014, 56, 27-36.

9. C. Johns, R. A. Shellie, O. G. Potter, J. W. O'Reilly, J. P. Hutchinson, R. M. Guijt, M. C. Breadmore, E. F. Hilder, G. W. Dicinoski and P. R. Haddad, J Chromatogr A, 2008, 1182, 205214.

10. B. R. McCord, I. Corbin and E. C. Bender, in Chapter 14: Chromatography of Explosives CRC Press, Boca Raton, FL, 2012. 
11. K. A. Hargadon and B. R. McCord, J Chromatogr, 1992, 602, 241-247.

12. K. G. Hopper, H. Leclair and B. R. McCord, Talanta, 2005, 67, 304-312.

13. P. Kolla, Journal of Chromatography, 1994, 674, 309-318.

14. D. Gaurav, A. K. Malik and P. K. Rai, Critical Reviews in Analytical Chemistry, 2007, 37, 227268.

15. S. Zitrin and T. Tamiri, in Chapter 16: Analysis of Explosives by Infrared Spectrometry CRC Press, Boca Raton, FL, 2012.

16. F. Zapata and C. Garcia-Ruiz, Spectrochim Acta A Mol Biomol Spectrosc, 2018, 189, 535-542.

17. K. Castro, S. Fdez-Ortiz de Vallejuelo, I. Astondoa, F. M. Goni and J. M. Madariaga, Anal Bioanal Chem, 2011, 400, 3065-3071.

18. D. Royds, S. W. Lewis and A. M. Taylor, Talanta, 2005, 67, 262-268.

19. R. G. Ewing, D. A. Atkinson, G. A. Eiceman and G. J. Ewing, Talanta, 2001, 54, 515-529.

20. L. A. Chesson, J. D. Howa, M. J. Lott and J. R. Ehleringer, Forensic Chemistry, 2016, 2, 9-14.

21. S. Benson, C. Lennard, P. Maynard and C. Roux, Forensic Sci Int, 2006, 157, 1-22.

22. H. Brust, M. Koeberg, A. van der Heijden, W. Wiarda, I. Mugler, M. Schrader, G. Vivo-Truyols, P. Schoenmakers and A. van Asten, Forensic Sci Int, 2015, 248, 101-112.

23. C. G. Fraga, A. V. Mitroshkov, N. S. Mirjankar, B. P. Dockendorff and A. M. Melville, Talanta, 2017, 174, 131-138.

24. N. S. Mirjankar, C. G. Fraga, A. J. Carman and J. J. Moran, Anal Chem, 2016, 88, 1827-1834.

25. S. J. Benson, C. J. Lennard, P. Maynard, D. M. Hill, A. S. Andrew and C. Roux, Sci Justice, 2009, 49, 73-80.

26. K. J. Johnson and R. E. Synovec, Chemometrics and Intelligent Laboratory Systems, 2002, 60, 225-237.

27. K. M. Pierce, J. L. Hope, K. J. Johnson, B. W. Wright and R. E. Synovec, J Chromatogr A, 2005, 1096, 101-110.

28. S. Yang, P. Li, J. Liu, X. Bi, Y. Ning, S. Wang and P. Wang, Ecotoxicol Environ Saf, 2019, 184, 109604.

29. C. Martin-Alberca, F. Zapata, H. Carrascosa, F. E. Ortega-Ojeda and C. Garcia-Ruiz, Talanta, 2016, 149, 257-265.

30. C. Martin-Alberca, M. A. de la Ossa, J. Saiz, J. L. Ferrando and C. Garcia-Ruiz, Electrophoresis, 2014, 35, 3272-3280. 